\title{
Article \\ Current Practices and Beliefs Regarding Screening Patients with Burns for Acute Stress Disorder and Posttraumatic Stress Disorder: A Survey of the American Burn Association Membership
}

\author{
Mallory B. Smith ${ }^{1,2, *}$, Shelley A. Wiechman ${ }^{3}$, Samuel P. Mandell ${ }^{4}$, Nicole S. Gibran ${ }^{5}$, Monica S. Vavilala ${ }^{1,6}$ and \\ Frederick P. Rivara 1,7
}

Citation: Smith, M.B.; Wiechman, S.A.; Mandell, S.P.; Gibran, N.S.; Vavilala, M.S.; Rivara, F.P. Current Practices and Beliefs Regarding Screening Patients with Burns for Acute Stress Disorder and Posttraumatic Stress Disorder: A Survey of the American Burn Association Membership. Eur. Burn J. 2021, 2, 215-225. https://doi.org/ $10.3390 /$ ebj2040016

Academic Editor: Naiem Moiemen

Received: 12 October 2021

Accepted: 28 October 2021

Published: 1 November 2021

Publisher's Note: MDPI stays neutral with regard to jurisdictional claims in published maps and institutional affiliations.

Copyright: (c) 2021 by the authors. Licensee MDPI, Basel, Switzerland. This article is an open access article distributed under the terms and conditions of the Creative Commons Attribution (CC BY) license (https:/ / creativecommons.org/licenses/by/ $4.0 /)$.
1 Harborview Injury Prevention \& Research Center, University of Washington, Seattle, WA 98104, USA; vavilala@uw.edu (M.S.V.); fpr@uw.edu (F.P.R.)

2 Division of Pediatric Critical Care Medicine, Department of Pediatrics, University of Washington, Seattle, WA 98105, USA

3 Department of Rehabilitation Medicine, University of Washington, Seattle, WA 98104, USA; wiechman@uw.edu

4 Division of Burn, Trauma, Acute and Critical Care Surgery, Department of Surgery, University of Texas Southwestern, Dallas, TX 75390, USA; samuel.mandell@utsouthwestern.edu

5 Division of Trauma, Critical Care, and Burn, Department of Surgery, University of Washington, Seattle, WA 98104, USA; nicoleg@uw.edu

6 Department of Anesthesiology and Pain Management, University of Washington, Seattle, WA 98104, USA

7 Division of General Pediatrics, Department of Pediatrics, University of Washington, Seattle, WA 98104, USA

* Correspondence: mbs0812@uw.edu or mallory.smith@seattlechildrens.org

\begin{abstract}
Stress disorders are common after burn injuries and universal screening is recommended. This study describes current screening practices and provider beliefs regarding screening for stress disorders in patients with burns in the US. This was a 31-question survey distributed to the American Burn Association. Sixty-two percent of 121 respondents indicated their institution formally screened for ASD and/or PTSD. The most common reason for not screening was a lack of mental healthcare providers $(46 \%)$, lack of funding $(26 \%)$ and lack of time $(20 \%)$. The timing of screening, the person administering the screening, and the method of screening varied for both pediatric and adult patients. Most respondents $(87 \%)$ believed screening should be a standard of care, but only $32 \%$ were comfortable screening pediatric patients and $62 \%$ were comfortable screening adults. While screening for ASD and PTSD is recommended for patients with burns, our study indicates that screening is not a current standard of care. Lack of mental healthcare providers, funding, and time are contributing factors. Among those institutions that screen, a uniform screening practice does not exist.
\end{abstract}

Keywords: burn; posttraumatic stress disorder; acute stress disorder; psychological screening

\section{Introduction}

Mortality rates after burn injuries in the United States (US) are low and have decreased for even the most severe burns in the last twenty years [1-3]. However, poor functional, social, and emotional outcomes are common among survivors of burn injuries [4-7]. Up to $20 \%$ of burn survivors have functional impairments five years after injury and $21-50 \%$ report problems with work [8]. As many as 13\% of survivors report their burn prevents them from making new friends, and 25\% report they are limited in what they can do for their family [5]. Scores on mental health and emotional functioning in burn survivors are below the national average up to three years after injury [9]. A diagnosis of Posttraumatic Stress Disorder (PTSD) is a risk factor for poor functional outcomes [10].

Acute Stress Disorder is defined by the Diagnostic and Statistical Manual of Mental Disorders-Fifth Edition (DSM-V) as the development of nine or more symptoms within 
any of the following categories: negative mood, avoidance, intrusion, arousal, or dissociation, within 3 days to 1 month after a traumatic event is experienced [11]. A diagnosis of PTSD requires at least one symptom from the intrusion category, persistent avoidance of stimuli associated with the traumatic event, negative alterations in cognition or mood associated with the event, and marked alterations in arousal or reactivity associated with the traumatic event that all occur for more than one month [11]. Given that a diagnosis of ASD cannot be made until at least three days after the trauma is experienced, patients with less severe burns, admitted for fewer than three days or treated as an outpatient, are difficult to screen in a systematic way.

Among burn survivors, the prevalence of Acute Stress Disorder (ASD) may be up to $30 \%$ and the prevalence of PTSD is as high as $42 \%$ at six months post-injury [12-14]. The criteria for a diagnosis of ASD or PTSD are fairly robust and the number of patients who experience symptoms of ASD and PTSD that are causing distress is even higher than those that meet the criteria for a diagnosis. Previous studies have found that one of the strongest factors associated with PTSD is the presence of ASD in the acute post-injury period [12,13]. Additionally, there is no clear pattern of injury etiology or circumstance most associated with the development of stress disorder symptoms [15]. It is therefore necessary to screen patients with burn injuries for symptoms of stress disorders throughout their recovery and intervene with patients who are symptomatic.

The American Burn Association (ABA) has made psychological screening and treatment a priority in the care of patients with burns. As of October 2019, the ABA requires centers to include brief psychological screening and intervention for burn center verification. In 2012, the ABA published a consensus statement recommending screening for ASD and PTSD in all burn patients as well as follow-up for patients with positive screens [16]. The current adherence to these recommendations by burn centers in the US is unknown. We surveyed the membership of the ABA to learn about the current screening practices for stress disorders by burn centers and healthcare provider beliefs regarding screening.

\section{Materials and Methods}

A 31-question survey was created using SurveyMonkey ${ }^{\mathrm{R}}$ and was designed based on the 7-step process described by Gelbach et al. and Dillman et al. $[17,18]$. The questions specifically assessed the practical aspects of PTSD and ASD screening at the respondent's institution and the individual respondent's beliefs regarding the importance of screening and how screening should be conducted. Question content was developed by the authors, who include an experienced rehabilitation psychologist (SAW), in consultation with a colleague with expertise in survey design. Cognitive interviews were performed to verify question clarity with four individuals from different backgrounds: two physicians, one psychologist, and one social worker. The survey was piloted among pediatric critical care faculty at our burn center. The final survey was reviewed and approved by the ABA Survey Advisory Panel.

The ABA distributed the survey to all US members actively caring for patients with burns via e-mail on two separate occasions. About 1500 members received the survey link and cover letter with information about consent and the purpose of the survey. In order to maintain confidentiality, no identifying information about the respondent or their institution was collected. It was important to maintain anonymity given the chance that a respondent might have reported beliefs that directly conflicted with the practices of their institution regarding the importance of screening for stress disorders. Therefore, the responses remained anonymous in order to encourage truthful answers. Some questions allowed more than one answer choice and percentages will equal more than $100 \%$.

\section{Results}

We received 121 survey responses over a 30-day period, and $90(74 \%)$ were completed in full. Of the 31 incomplete surveys, 27 respondents indicated their institution screened for stress disorders, three indicated they did not, and one respondent was unsure if their 
institution screened. The questions that were incomplete included the specific questions about screening practices, and only four of the 31 respondents on incomplete surveys answered the last section on personal beliefs. The respondents of the completed surveys were mostly surgeons (27\%) and nurses (31\%). Of the 90 surveys completed in full, 11 were completed by a current medical director. About half of the respondents had greater than 10 years of experience working with burns (Table 1).

Table 1. Respondent characteristics.

\begin{tabular}{|c|c|c|c|}
\hline & $\begin{array}{l}\text { Screened for ASD/PTSD } \\
\qquad N=48\end{array}$ & $\begin{array}{c}\text { Did Not Screen for } \\
\text { ASD/PTSD } \\
\mathbf{N}=32\end{array}$ & $\begin{array}{l}\text { Unsure If Institution } \\
\text { Screened } \\
\mathbf{N}=\mathbf{1 1}\end{array}$ \\
\hline \multicolumn{4}{|l|}{ Profession, $\mathrm{n}$} \\
\hline Surgeon & 11 & 10 & 3 \\
\hline Physician (non-surgeon) & 1 & 1 & 0 \\
\hline $\mathrm{APP}^{1}$ & 8 & 3 & 1 \\
\hline Nurse & 13 & 8 & 2 \\
\hline Psychologist/CLS ${ }^{2} / \mathrm{SW}^{3}$ & 5 & 4 & 0 \\
\hline $\mathrm{PT} / \mathrm{OT}$ & 3 & 4 & 4 \\
\hline Other & 7 & 2 & 1 \\
\hline Medical Director ${ }^{4}, \mathrm{n}$ & 5 & 5 & 1 \\
\hline \multicolumn{4}{|l|}{ Years of Experience, $\mathrm{n}$} \\
\hline $0-5$ years & 9 & 7 & 3 \\
\hline $6-10$ years & 13 & 8 & 3 \\
\hline $11-15$ years & 9 & 2 & 2 \\
\hline$>15$ years & 17 & 14 & 2 \\
\hline
\end{tabular}

${ }^{1}$ Advanced Practice Provider; ${ }^{2}$ Child Life Specialist; ${ }^{3}$ Social Worker; ${ }^{4}$ All medical directors were also surgeons.

3.1. Some Institutions Do Not Meet the American Burn Association's Standards for ASD/PTSD Screening

Seventy-five of the 121 respondents indicated their institution formally screens for symptoms of stress disorders, and 35 respondents indicated they did not. The most common reason for not screening was a lack of mental healthcare providers (46\%) followed by lack of funding $(26 \%)$ and lack of time $(20 \%)$. Of the respondents who indicated their institution did formally screen, 21 worked at institutions that cared for adults only, two worked at institutions that cared for pediatric patients only, and 52 worked at institutions that cared for pediatric and adult patients both.

\subsection{Screening Practices Vary between Institutions}

Most of the respondents who cared for pediatric patients worked at institutions that admitted more than 75 patients with a burn injury per year (62\%). Most screened adolescents $13-17$ years old $(63 \%)$, but younger children were screened less frequently (4-5 years, 33\%; 6-7 years, 37\%; 8-9 years, 50\%; 10-12 years, 53\%). Less than half (43\%) of the institutions screened all pediatric patients with a burn injury and a quarter screened only those admitted to the hospital. The most common mechanism of screening was a formal evaluation by psychology or psychiatry (56\%) or a social worker (52\%), and many indicated they used formal screening tools (Figure 1). The two most common times that screening was performed were during the inpatient stay and within the first month after discharge (Figure S1). For patients who screened positive, most respondents reported their institutions made referrals to inpatient (73\%) and outpatient (70\%) psychology or psychiatry. Most respondents also indicated their institution initiated inpatient services such as pet therapy or music therapy for patients who screened positive. Approximately $37 \%$ of institutions indicated that they have adopted a trauma-informed care approach in their burn center. Medications were used infrequently (Table 2). 


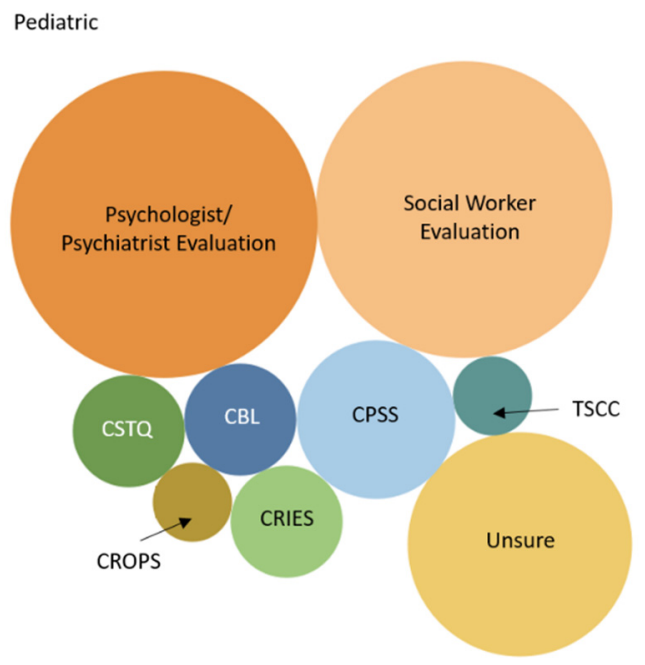

(a)

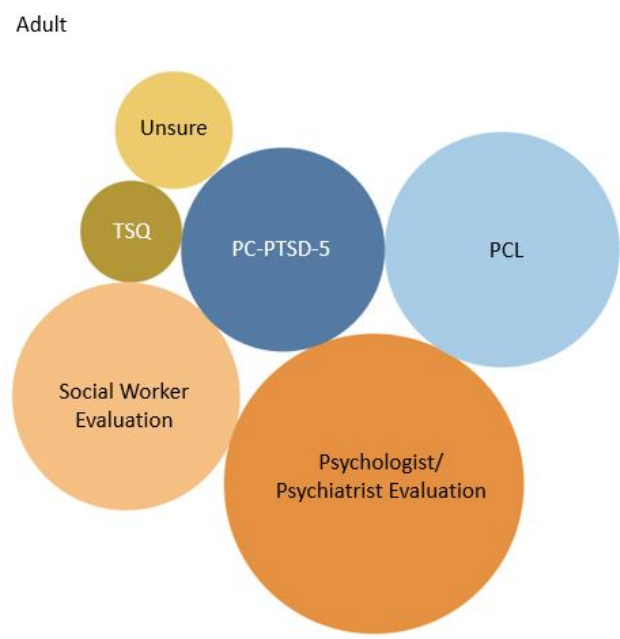

(b)

Figure 1. The methods utilized for screening for stress disorder symptoms at the respondent's institution are depicted. The area of the circle represents the number of respondents who selected the screening method as a way their institution screens for stress disorder symptoms. Respondents were able to select more than one method. (a) Pediatric screening tools: CTSQ—Child Trauma Screening Questionnaire; CROPS—Child Report of Post-Traumatic Symptoms; CBL—Child Behavior Checklist; CRIES—Child Impact of Events Scale; CPSS—Child PTSD Symptom Scale; TSCC—Trauma Symptom Checklist for Children (b) Adult screening tools: TSQ_Trauma Screening Questionnaire; PC-PTSD-5_-Primary Care PTSD Screen for DSM-V; PCL-PTSD Checklist.

Table 2. Screening Practices.

\begin{tabular}{|c|c|c|}
\hline & Adult & Pediatric \\
\hline & $\mathrm{N}=47$ & $\mathbf{N}=30$ \\
\hline \multicolumn{3}{|l|}{ Which population does your institution screen?, n } \\
\hline All patients with a burn & 33 & 14 \\
\hline Only patients admitted to the intensive care unit & 2 & 1 \\
\hline Only patients admitted to the hospital & 11 & 7 \\
\hline Only patients with a burn over a certain TBSA cut-off & 0 & 0 \\
\hline Only patients with injury severity score cut-off & 1 & 1 \\
\hline Only patients with a certain type of burn injury mechanism & 0 & 0 \\
\hline I am unsure & 0 & 6 \\
\hline \multicolumn{3}{|l|}{ Who performs the screening at your institution?, n } \\
\hline Attending Surgeon & 6 & 1 \\
\hline Surgical Trainee & 2 & 1 \\
\hline Advance Practice Provider & 15 & 5 \\
\hline Nurse & 22 & 10 \\
\hline Social Worker & 17 & 13 \\
\hline Child Life Specialist & NA & 9 \\
\hline Psychologist & 26 & 16 \\
\hline Another Medical Team & 1 & 2 \\
\hline I am unsure & 0 & 2 \\
\hline
\end{tabular}


Table 2. Cont.

\begin{tabular}{|c|c|c|}
\hline & Adult & Pediatric \\
\hline & $\mathrm{N}=47$ & $\mathbf{N}=30$ \\
\hline \multicolumn{3}{|c|}{$\begin{array}{l}\text { Once a patient screens positive for stress disorder symptoms, what is the next step at your } \\
\text { institution?, n }\end{array}$} \\
\hline Continue to monitor and repeat screening & 23 & 12 \\
\hline Treat with Trauma-Informed Care & 18 & 11 \\
\hline Referral for inpatient therapies (recreation, music, pet, etc.) & 14 & 16 \\
\hline Referral for inpatient Psychology/Psychiatry & 34 & 21 \\
\hline Referral for outpatient Psychology/Psychiatry & 34 & 22 \\
\hline Initiation of beta-blockers & 6 & 1 \\
\hline Initiation of selective serotonin reuptake inhibitors & 15 & 3 \\
\hline Initiation of other anti-depressants & 10 & 0 \\
\hline Initiation of anti-psychotics & 5 & 0 \\
\hline I am unsure & 1 & 3 \\
\hline
\end{tabular}

Respondents were allowed to select more than one response for each question.

About half $(47 \%)$ of the institutions represented by respondents caring for adults admitted more than 300 adult patients with a burn injury per year, and only $6 \%$ represented institutions that admitted less than 100 adults per year. Most screened all adult patients with a burn, but $23 \%$ only screened those admitted to the hospital. The most common method for screening was a formal evaluation by psychology or psychiatry $(55 \%)$ or a social worker $(32 \%)$. The adult institutions relied more on formal screening tools (Figure 1). The PTSD Checklist (PCL) was used by $34 \%$ of respondents and the Primary Care PTSD Screen for DSM-V (PC-PTSD-5) was used by $26 \%$. The timing of screening was very similar to the timing for pediatric patients (Figure S1). After an adult patient screened positive, most respondents indicated their institutions made a referral for inpatient and outpatient psychology or psychiatry $(72 \%)$, half continued to monitor and repeated the screening, and over a third relied on a trauma-informed care approach to treatment. The most common medications prescribed were selective serotonin reuptake inhibitors $(32 \%)$ followed by other anti-depressants (21\%) and beta-blockers (13\%) (Table 2). Figure S1 in the Supplementary Materials contains detailed results regarding screening times reported by respondents.

\subsection{Providers Who Care for Patients with Burn Injuries Support Screening for ASD/PTSD}

The majority of respondents indicated screening for stress disorders as part of the treatment for a burn injury was very important for pediatric $(83 \%)$ and adult $(87 \%)$ patients (Figure S2). Additionally, $87 \%$ of respondents thought screening for stress disorders should be standard of care. Of the remaining $13 \%$, most were unsure and only $3 \%$ indicated it should not be. All respondents who believed screening should not be standard of care were surgeons working in institutions that did not screen and two were the medical directors of their institution (Table 3). Figure S2 in the Supplementary Materials contains detailed results of respondent beliefs regarding the importance of screening for stress disorders. 
Table 3. Respondent's beliefs regarding screening patients with burn injuries for stress disorder symptoms.

\begin{tabular}{|c|c|c|c|c|}
\hline & Surgeons & Medical Directors & $\begin{array}{l}\text { Psychologists/ } \\
\text { CLS }^{1} / \mathrm{SW}^{2}\end{array}$ & Other HCP ${ }^{3}$ \\
\hline \multicolumn{5}{|l|}{ Should screening be standard of care? (\%) } \\
\hline Yes & 75 & 73 & 100 & 88 \\
\hline No & 12.5 & 18 & 0 & 0 \\
\hline Unsure & 12.5 & 9 & 0 & 12 \\
\hline \multicolumn{5}{|c|}{$\begin{array}{l}\text { How much personal responsibility do you } \\
\text { feel for screening? }(\%)\end{array}$} \\
\hline Very Little & 0 & 0 & 0 & 2 \\
\hline Little & 8 & 9 & 0 & 4 \\
\hline Neutral & 8 & 0 & 0 & 22 \\
\hline Some & 38 & 28 & 22 & 33 \\
\hline A Lot & 46 & 64 & 78 & 39 \\
\hline Prefer to not reply & 0 & 0 & 0 & 0 \\
\hline \multicolumn{5}{|c|}{$\begin{array}{l}\text { Who do you believe should have the primary } \\
\text { responsibility for screening? }(\%)\end{array}$} \\
\hline Attending Surgeon & 50 & 55 & 0 & 31 \\
\hline Surgical Trainee & 21 & 18 & 0 & 8 \\
\hline Advanced Practice Provider & 46 & 64 & 11 & 29 \\
\hline Nurse & 42 & 55 & 11 & 47 \\
\hline Social Worker & 46 & 55 & 56 & 63 \\
\hline Child Life Specialist & 42 & 28 & 22 & 45 \\
\hline Psychologist/Psychiatrist & 71 & 64 & 44 & 63 \\
\hline Another Physician Service & 8 & 9 & 0 & 8 \\
\hline Primary Care Physician & 8 & 9 & 0 & 12 \\
\hline Unsure & 4 & 0 & 11 & 6 \\
\hline
\end{tabular}

${ }^{1}$ Child Life Specialist; ${ }^{2}$ Social Worker; ${ }^{3}$ Healthcare Providers. Respondents were able to select more than one response.

Most respondents felt personal responsibility for screening patients for stress disorders, but psychologists, physical and occupational therapists, and social workers felt more personal responsibility compared to their colleagues (95\% indicated "some" or "a lot" vs. $83 \%$ of surgeons, $67 \%$ of advanced practice providers, and $61 \%$ of nurses; Fischer's exact $p=0.028$ ).

In addition to ASD and PTSD, respondents felt they should be screening for other psychosocial conditions as part of the treatment for a burn injury. Depression, substance abuse, suicidal ideation/self-harm, and anxiety were selected by more than $90 \%$ of respondents as important conditions for which to screen. Screening for domestic violence was selected by $83 \%$ and housing and food insecurity by about half of respondents.

\subsection{Many Healthcare Professionals Are Uncomfortable Screening for Stress Disorders}

Only $32 \%$ of respondents were comfortable screening pediatric patients while $62 \%$ were comfortable screening adult patients. In general, all professions were more comfortable screening adults than pediatric patients, but nurses were significantly less comfortable screening pediatric patients compared to other professions $(48 \%$ vs. $33 \%$ of advanced practice providers, $26 \%$ of therapists and social workers, and $25 \%$ of surgeons; Fischer's exact $p=0.024$ ). There was no consensus about which healthcare professionals should have the primary responsibility for screening (Table 3). Lastly, for some questions asking about screening practices at the respondent's institution, up to $35 \%$ of respondents indicated they were unsure of the correct answer indicating they may have not been familiar with the protocol.

\section{Discussion}

The results of this survey indicate many institutions caring for patients with burn injuries meet the standard set by the ABA for screening for stress disorders, and most 
providers believe screening is important and should be standard of care. However, it is clear that more guidance is needed on appropriate screening protocols as there are many institutions that do not meet the standard. The US Department of Veteran Affairs, Veterans Health Administration recently published guidelines for improving their care for veterans with PTSD. Their roadmap included leadership support, alignment of procedures across institutions, and education for healthcare providers [19]. A similar set of standard procedures with detailed processes for screening and follow-up of at-risk patients would increase the equity and quality of care for patients with burn injuries in the US.

In addition, even though most respondents indicated their institutions' screen for stress disorders, the practices varied. Patients with less severe burn injuries were not screened at some institutions. This is worrisome given that patients with minor injuries do develop PTSD [20,21]. In institutions that care for pediatric patients, adolescents were most commonly screened but there was no consensus across institutions on which ages to screen. This likely results in many younger children with a high risk for PTSD going unrecognized $[22,23]$. The timing of screening was consistent between adult and pediatric centers and occurred prior to discharge and within the first month after discharge. However, very few institutions screened after the first month. This too likely results in patients who develop PTSD later in their recovery being missed [12,24]. Such discrepancies in screening practices may lead to inequities in care and are likely due to the challenges that exist in screening for ASD/PTSD.

There are several challenges to screening for ASD and PTSD that were highlighted by this survey. First, these results highlight the important role of mental health care providers in the care of patients with burn injuries. The lack of mental health care providers to either inform the screening process or who are accessible for follow-up on a positive screen was a major reason that institutions did not screen. Conversely, in institutions that did screen, psychologists, psychiatrists, and social workers performed most of the screening and felt the most comfortable with screening. The ABA verification requirements specify that a psychologist or psychiatrist should be available for adult patients, but this same requirement is not specified for pediatric patients. There is also no determination of how many full-time equivalents should be dedicated to patients with burns. Increased leadership support to enhance the role of mental health providers on burn teams would be a step towards improving the outcomes of patients with burn injuries in the US.

A second challenge is the lack of appropriate screening tools, particularly for children and inpatients. Most of the screening tools are either for PTSD (not deemed appropriate for ASD) or are too long and are not considered a screening tool but a tool for diagnostic assessment. It is also important to note that screening in the first three days of the trauma would not be considered valid, so many patients may be missed if they have a short inpatient stay. One approach to screening that seems particularly relevant for burn centers is to screen for risk factors for ASD/PTSD. There are two screening tools that were developed to assess for risk factors for the development of PTSD. The Child Trauma Screening Questionnaire (CTSQ) (a 10-item measure) and the Screening Tool for Early Predictors of Posttraumatic Stress Disorder (STEPP) (also a 10-item measure) [25,26]. These measures can be administered by anyone on the team, and referrals for further assessment with a mental health provider can be made for those patients who screen positive for risk factors. The benefit of this approach is that there is no need to wait for the emergence of symptoms in order to identify the patients who may be at risk and in need of closer monitoring. This is a crucial benefit in a busy burn and trauma center where time and resources are limited.

The third challenge to screening is what to do with those who screen positive for acute stress symptoms, particularly in light of the recognition that the presence of acute stress symptoms are universal immediately following a serious trauma such as a burn injury and recovery can take several months. The emergence of PTSD is a delay or disruption of the normal recovery process, rather than the onset of psychopathology. In other words, PTSD develops when a person's own coping resources have not been able to adequately process the trauma and eliminate the initial symptoms of the instinctual fight-flight- 
freeze response [27]. Evidence-based treatment for both ASD and PTSD is cognitive behavior therapy (both exposure-based therapies and cognitive therapies) as the first-line treatment. This treatment is typically $8-10,60-\mathrm{min}$ sessions with homework between sessions. Clinicians caution against beginning this treatment within two weeks of trauma exposure-delaying this treatment allows the individual additional time for transient symptoms and post-trauma stressors to resolve. Further, treatment should not begin until other stressful events from the trauma have abated, such as pain, surgery, and any legal proceedings [28]. Adjunctive pharmacotherapy (SRI, SSRI) can be considered as a second-line treatment if CBT is not effective [28]. Treatment for PTSD is not administered prophylactically in the early stages of the trauma and the absence of PTSD symptoms is a contraindication for PTSD treatment even in the weeks following the trauma. However, there is an emerging philosophy of care (Trauma-Informed Care) that can be implemented in the early stages of trauma in both the inpatient and outpatient settings with the hope of mediating symptoms of acute stress and reducing the risk of the development of PTSD $[29,30]$. Within this philosophy of care is the recognition that the medical environment and treatment for burns can in and of itself be an additional trauma and providers need to minimize the distress of treatment. It also recognizes that many patients have histories of past traumas that can be exacerbated by entering the medical environment. Part of trauma-informed care is a universal screening of risk factors for all patients, with steppedup interventions for those most at risk. A second key aspect of trauma-informed care is that every member of the medical team is trained to minimize distressing symptoms of the medical environment-from the person that answers the call for an appointment to the housekeepers to the surgeon. All members are trained to do their work in a way that makes the environment a safe place with such interventions as patient-centered care, minimizing the startle response, respecting privacy and autonomy, and minimizing pain. This philosophy of care takes administrative and financial support for training. However, reducing the traumatic nature of the hospitalization may improve healing and decrease the number of surgeries needed and hospital length of stay [31]. It is important to note that interventions such as relaxation training, art/music or pet therapy have not shown to be effective in reducing ASD/PTSD symptoms when used alone, but future studies may consider examining whether or not these adjunctive treatments are an effective component of trauma-informed care.

With these parameters in mind, burn centers need to carefully consider how to implement appropriate screening, by whom, and what to do with the results of the screening for both inpatient and outpatient settings. As more institutions are examining the effect of burn injuries on psychosocial outcomes, it will continue to be important to collaborate nationally. The screening methods reported in this study included numerous screening tools each with different psychometric properties and scoring scales. Synthesizing data across centers would be more feasible if there were a common set of measurement tools used across institutions $[32,33]$. Ideally, standard recommendations will be adopted nationally that include tools for both adults and pediatrics that can be used to screen for risk factors for the development of ASD/PTSD. Guidelines should also include referrals to mental health professionals to further assess and determine a treatment plan where needed. Burn centers can consider initiating philosophies of care, such as trauma-informed care, that minimize the traumatic nature of burn care and hopefully curtail the development of PTSD symptoms.

Lastly, even for institutions that are screening for symptoms of stress disorders, more work is needed to educate healthcare professionals. It is likely that the respondents who terminated the survey early were unfamiliar with the screening practices at their institution. It is also possible that the low response rate is due to a lack of knowledge about or engagement with stress disorder screening by ABA members. Nurses as a group were most uncomfortable screening for stress disorders and yet were thought to hold the primary responsibility for screening by some other healthcare professionals. In-services targeted at 
increasing the comfort level of providers with screening may increase the frequency and quality of screening [34].

The study is limited by the low response rate and the inability to know how many centers are represented by the respondents due to the anonymous nature of the study. While we cannot calculate the accurate prevalence of screening for stress disorders in US burn centers, the data do indicate that there is variation in practice and that some centers do not screen. According to the ABA website, there are 115 centers in the US that provide care to patients with burn injuries, and 63 of those centers are verified burn centers. Given there were eleven medical directors among our respondents and the variation in the number of admissions per year reported, we can assume the respondents of our survey represent multiple different centers. Our results may be biased given individuals who consider stress disorders to be an important component of the care of individuals with burns would be more likely to take the survey.

\section{Conclusions}

Results of this survey found that even though the majority of respondents feel that screening for ASD/PTSD is important, some centers caring for patients with burn injuries do not meet the standard set by the American Burn Association for screening of stress disorders. Among the centers that do meet the standard, the practices vary, likely resulting in inequities in care. Standardized screening protocols, increased support for mental health providers on burn teams, and more access to education about stress disorders and traumainformed care would likely improve the long-term outcomes of patients with burn injuries and aid in national research efforts.

Supplementary Materials: The following are available online at https:/ /www.mdpi.com/article/ 10.3390/ebj2040016/s1, Figure S1: Timeline of screening for stress disorder symptoms, Figure S2: How important is it to screen patients for stress disorder symptoms as part of their burn treatment?

Author Contributions: M.B.S. conceptualized and designed the study, analyzed the data, drafted the initial manuscript, and reviewed and revised the manuscript. S.A.W. conceptualized and designed the study, drafted the initial manuscript, and reviewed and revised the manuscript. F.P.R., M.S.V. and S.P.M. conceptualized and designed the study and reviewed and revised the manuscript. N.S.G. assisted in survey distribution and reviewed and revised the manuscript. All authors have read and agreed to the published version of the manuscript.

Funding: The contents of this paper were developed in part with funding from NICHD grant T32 HD057822-11 and the Seattle Children's Guild Association Endowed Chair in Pediatrics. There was no APC for this article.

Institutional Review Board Statement: The study was conducted according to the guidelines of the Declaration of Helsinki and approved by the Institutional Review Board of the University of Washington (STUDY00010251 date of approval 5/4/2020).

Informed Consent Statement: Informed consent was obtained from all subjects involved in the study.

Data Availability Statement: The data presented in this study are available on request from the corresponding author. The data are not publicly available due to limitations in the IRB protocol, but a modification can be made for sharing purposes.

Acknowledgments: The authors would like to acknowledge Jimmy Beck for his consultation on survey design, Emma R. Duchin and Hanne M. Boveng for their time assisting in data analysis, and Gretchen Carrougher for her assistance in spreading awareness about the survey.

Conflicts of Interest: The authors declare no conflict of interest. The funders had no role in the design of the study; in the collection, analyses, or interpretation of data; in the writing of the manuscript, or in the decision to publish the results. 


\section{References}

1. Wolf, S.E.; Rose, J.K.; Desai, M.H.; Mileski, J.P.; Barrow, R.E.; Herndon, D.N. Mortality determinants in massive pediatric burns. An analysis of 103 children with $>$ or $=80 \%$ TBSA burns ( $>$ or $=70 \%$ full-thickness). Ann. Surg. 1997, 225, 554-565. [CrossRef]

2. Brusselaers, N.; Hoste, E.A.; Monstrey, S.; Colpaert, K.E.; De Waele, J.J.; Vandewoude, K.H.; Blot, S.I. Outcome and changes over time in survival following severe burns from 1985 to 2004. Intensive Care Med. 2005, 31, 1648-1653. [CrossRef]

3. Ryan, C.M.; Schoenfeld, D.A.; Thorpe, W.P.; Sheridan, R.L.; Cassem, E.H.; Tompkins, R.G. Objective estimates of the probability of death from burn injuries. N. Engl. J. Med. 1998, 338, 362-366. [CrossRef]

4. Gerber, L.H.; Bush, H.; Holavanahalli, R.; Esselman, P.; Schneider, J.; Heinemann, A.; Garfinkel, S.; Cai, C. A scoping review of burn rehabilitation publications incorporating functional outcomes. Burns 2019, 45, 1005-1013. [CrossRef] [PubMed]

5. Ohrtman, E.A.; Shapiro, G.D.; Simko, L.C.; Dore, E.; Slavin, M.D.; Saret, C.; Amaya, F.; Lomelin-Gascon, J.; Ni, P.; Acton, A.; et al. Social Interactions and Social Activities After Burn Injury: A Life Impact Burn Recovery Evaluation (LIBRE) Study. J. Burn Care Res. 2018, 39, 1022-1028. [CrossRef] [PubMed]

6. Brady, K.J.S.; Grant, G.G.; Stoddard, F.J.; Meyer, W.J.; Romanowski, K.S.; Chang, P.H.; Painting, L.E.; Fowler, L.A.; Nelson, J.K.; Rivas, P.; et al. Measuring the Impact of Burn Injury on the Parent-Reported Health Outcomes of Children 1 to 5 Years: A Conceptual Framework for Development of the Preschool Life Impact Burn Recovery Evaluation Profile CAT. J. Burn Care Res. 2020, 41, 84-94. [CrossRef] [PubMed]

7. Davydow, D.S.; Katon, W.J.; Zatzick, D.F. Psychiatric morbidity and functional impairments in survivors of burns, traumatic injuries, and ICU stays for other critical illnesses: A review of the literature. Int. Rev. Psychiatry 2009, 21, 531-538. [CrossRef] [PubMed]

8. van Baar, M.E.; Essink-Bot, M.L.; Oen, I.M.; Dokter, J.; Boxma, H.; van Beeck, E.F. Functional outcome after burns: A review. Burns 2006, 32, 1-9. [CrossRef]

9. Spronk, I.; Legemate, C.; Oen, I.; van Loey, N.; Polinder, S.; van Baar, M. Health related quality of life in adults after burn injuries: A systematic review. PLoS ONE 2018, 13, e0197507. [CrossRef]

10. Cakir, U.; Terzi, R.; Abaci, F.; Aker, T. The prevalence of post-traumatic stress disorder in patients with burn injuries, and their quality of life. Int. J. Psychiatry Clin. Pract. 2015, 19, 56-59. [CrossRef]

11. American Psychiatric Association. Diagnostic and Statistical Manual of Mental Disorders, 5th ed.; American Psychiatric Association: Arlington, VA, USA, 2013.

12. Giannoni-Pastor, A.; Eiroa-Orosa, F.J.; Fidel Kinori, S.G.; Arguello, J.M.; Casas, M. Prevalence and Predictors of Posttraumatic Stress Symptomatology Among Burn Survivors: A Systematic Review and Meta-Analysis. J. Burn Care Res. 2016, 37, e79-e89. [CrossRef]

13. McKibben, J.B.; Bresnick, M.G.; Wiechman Askay, S.A.; Fauerbach, J.A. Acute stress disorder and posttraumatic stress disorder: A prospective study of prevalence, course, and predictors in a sample with major burn injuries. J. Burn Care Res. 2008, 29 , 22-35. [CrossRef]

14. Zheng, H.; Wu, K.; Zhou, Y.; Fu, L.; Zhang, D.; Liu, Z. Prevalence and associated factors of post-traumatic stress disorder in burned patients and their family members. Burns 2020, 47, 1102-1109. [CrossRef]

15. Oaie, E.; Piepenstock, E.; Williams, L. Risk factors for peri-traumatic distress and appearance concerns in burn-injured inpatients identified by a screening tool. Scars Burn. Heal. 2018, 4, 2059513118765294. [CrossRef]

16. Gibran, N.; Wiechman, S.; Meyer, W. Summary of the 2012 ABA Burn Quality Consensus Conference. J. Burn. Care Res. 2013, 34, 361-385. [CrossRef] [PubMed]

17. Gehlbach, H.; Artino, A.R., Jr. The Survey Checklist (Manifesto). Acad. Med. 2018, 93, 360-366. [CrossRef] [PubMed]

18. Dillman, D.A.; Smyth, J.D.; Christian, L.M. Internet, Phone, Mail, and Mixed-Mode Surveys: The Tailored Design Method. John Wiley \& Sons, Incorporated, 2014. ProQuest Ebook Central. Available online: https://ebookcentral.proquest.com/lib/ washington/detail.action?docID=1762797 (accessed on 13 December 2020).

19. Crowe, C.; Collie, C.; Johnson, C.; Wiltsey Stirman, S. An intervention mapping process to increase evidence-based psychotherapy within a complex healthcare system. Am. Psychol. 2020, 75, 1116-1129. [CrossRef] [PubMed]

20. Malt, U.F.; Ugland, O.M. A long-term psychosocial follow-up study of burned adults. Acta Psychiatr. Scand Suppl. 1989, 355, 94-102. [CrossRef] [PubMed]

21. Boersma-van Dam, E.; van de Schoot, R.; Hofland, H.W.C.; Engelhard, I.M.; Van Loey, N.E.E. Individual recovery of health-related quality of life during 18 months post-burn using a retrospective pre-burn measurement: An exploratory study. Qual. Life Res. 2021, 30, 737-749. [CrossRef]

22. Rennick, J.E.; Johnston, C.C.; Dougherty, G.; Platt, R.; Ritchie, J.A. Children's psychological responses after critical illness and exposure to invasive technology. J. Dev. Behav. Pediatr. 2002, 23, 133-144. [CrossRef]

23. Xi, M.M.; Lei, F.; Xie, W.G. Advances in the research of psychological rehabilitation of pediatric burn patients. Zhonghua Shao Shang Za Zhi 2020, 36, 519-522. (In Chinese) [PubMed]

24. Visser, E.; Gosens, T.; Den Oudsten, B.L.; De Vries, J. The course, prediction, and treatment of acute and posttraumatic stress in trauma patients: A systematic review. J. Trauma Acute Care Surg. 2017, 82, 1158-1183. [CrossRef] [PubMed]

25. Daviss, W.B. The Child Trauma Screening Questionnaire predicts PTSD onset 6 months after traumatic accident better than the Children's Impact of Events Scale. Evid. Based Ment. Health 2007, 10, 44. [CrossRef] 
26. van Meijel, E.P.; Gigengack, M.R.; Verlinden, E.; Opmeer, B.C.; Heij, H.A.; Goslings, J.C.; Bloemers, F.W.; Luitse, J.S.; Boer, F.; Grootenhuis, M.A.; et al. Predicting posttraumatic stress disorder in children and parents following accidental child injury: Evaluation of the Screening Tool for Early Predictors of Posttraumatic Stress Disorder (STEPP). BMC Psychiatry 2015, 15, 113. [CrossRef]

27. Foa, E.B.; Steketee, G.; Olasov Rothbaum, B. Behavioral/cognitive conceptualizations of post-traumatic stress disorder. Behav. Ther. 1989, 20, 155-176. [CrossRef]

28. Stein, M.B. Psychotherapy and Psychosocial Interventions for Posttraumatic Stress Disorder in Adults. 2021. Available online: https:/ / www.uptodate.com/contents/psychotherapy-and-psychosocial-interventions-for-posttraumatic-stress-disorderin-adults (accessed on 27 September 2021).

29. Harris, M.; Fallot, R.D. Envisioning a trauma-informed service system: A vital paradigm shift. New Dir. Ment. Health Serv. 2001, 89, 3-22. [CrossRef] [PubMed]

30. Oral, R.; Ramirez, M.; Coohey, C.; Nakada, S.; Walz, A.; Kuntz, A.; Benoit, J.; Peek-Asa, C. Adverse childhood experiences and trauma informed care: The future of health care. Pediatr. Res. 2016, 79, 227-233. [CrossRef]

31. O'Brien, K.H.; Lushin, V. Examining the Impact of Psychological Factors on Hospital Length of Stay for Burn Survivors: A Systematic Review. J. Burn Care Res. 2019, 40, 12-20. [CrossRef] [PubMed]

32. Kazis, L.E.; Marino, M.; Ni, P.; Soley Bori, M.; Amaya, F.; Dore, E.; Ryan, C.M.; Schneider, J.C.; Shie, V.; Acton, A.; et al. Development of the life impact burn recovery evaluation (LIBRE) profile: Assessing burn survivors' social participation. Qual. Life Res. 2017, 26, 2851-2866. [CrossRef] [PubMed]

33. Richard, R.; Baryza, M.J.; Carr, J.A.; Dewey, W.S.; Dougherty, M.E.; Forbes-Duchart, L.; Franzen, B.J.; Healey, T.; Lester, M.E.; Li, S.K.; et al. Burn rehabilitation and research: Proceedings of a consensus summit. J. Burn Care Res. 2009, 30, 543-573. [CrossRef] [PubMed]

34. Moss, K.M.; Ziviani, J.; Newcombe, P.; Cobham, V.E.; McCutcheon, H.; Montague, G.; Kenardy, J. Pathways to increasing the use of psychosocial care with hospitalized children. Psychol. Serv. 2019, 16, 29-37. [CrossRef] [PubMed] 